\title{
KAJIAN PENGGUNAAN PERISIAN SKETCHUP TERHADAP PENINGKATAN PENCAPAIAN PELAJAR DALAM TOPIK GEOMETRI BAGI SUBJEK MATEMATIK KEJURUTERAAN SATU (BA101)
}

\author{
HASNI BIN MAHMOOD*
}

\begin{abstract}
Abstrak
Subjek matematik kejuruteraan satu merupakan subjek yang diwajib lulus bagi pelajar semester satu Politeknik Malaysia. Salah satu masalah pelajar yang mengambil subjek tersebut di Politeknik Kota Bharu ialah penguasaan dalam topik geometri. Pelajar menghadapi kesukaran apabila menjawab soalan berkaitan dengan pengiraan isipadu berbanding pengiraan luas. Kelemahan utama di kalangan pelajar ialah keupayaan daya visualisasi mereka apabila melibatkan soalan yang berkaitan lukisan geometri tiga dimensi (3D). Salah satu perisian yang membolehkan pensyarah meningkatkan kemahiran daya visualisasi pelajar ialah SketchUp versi asas untuk pendidikan. Kajian ini bertujuan untuk mengenalpasti keberkesanan penggunaan perisian SketchUp versi asas dalam meningkatkan pencapaian bagi topik geometri yang merupakan salah satu topik dalam subjek matematik kejuruteraan satu (BA101). Seramai 30 orang pelajar dari Jabatan Kejuruteraan Awam, Jabatan Kejuruteraan Elektrik dan Jabatan Kejuruteraan Mekanikal di Politeknik Kota Bharu terlibat sebagai sampel kajian. Kajian ini dijalankan dengan menggunakan rekabentuk eksperimen ujian pra dan pos. Data kajian dianalisis dengan menggunakan perisian SPSS (Statistical Package For Social Science) versi 20. Hasil kajian menunjukkan selepas penggunaan perisian SketchUp di dalam kelas, didapati bahawa terdapat perbezaan markah yang signifikan di antara ujian pra dan ujian pos iaitu sebanyak $12.67 \%$. Hasil dari ujian-t telah menunjukkan bahawa terdapat perbezaan yang signifikan antara markah pra dan pos di mana nilai $t=4.519$. Dapatan kajian $(\rho=0.000, S D=15.35)$ menunjukkan berlakunya peningkatan dalam penggunaan perisian SketchUp setelah dilakukan rawatan. Dapatan ini menunjukkan bahawa kaedah pembelajaran menggunakan perisian Google SktechUp versi asas ini dapat meningkatkan pencapaian pelajar terhadap pembelajaran topik geometri dalam kelas matematik kejuruteraan satu di Politeknik Kota Bharu.
\end{abstract}

Kata kunci: daya visualisasi, geometri, perisian SketchUp

* Pensyarah Kanan di Jabatan Matematik, Sains \& Komputer, Politeknik Kota Bharu, Kelantan 


\begin{abstract}
Engineering Mathematics is a compulsory subject to pass for semester one students of Polytechnic Malaysia. One of the problems of students taking the mathematics subject at the Polytechnic Kota Bharu is to master in geometry topics. Students encounter difficulties when answering questions related to the calculation of the volume compared to the area calculation. The main weaknesses among students are the ability to visualize in $3 D$ when it comes to questions involving geometric three dimensional drawings (3D). One software that allows lecturers to improve the visualization skill of student is the basic education version of Sketch Up. This study aimed to identify the effectiveness of the use of the basic version of the SketchUp software to improve the performance of geometry topics. A total of 30 students from the Department of Civil Engineering, Electrical Engineering and Mechanical Engineering from Polytechnic Kota Bharu were involved in the study. The study was conducted using pre and post experimental tests. Data were analyzed using SPSS (Statistical Package for Social Sciences) version 20. It was found that after using Sketch Up software in classroom there are significant differences in the scores between pretest and post-test that is by $12.67 \%$. The results of $t$-test showed that there were significant differences between pre and post marks where the $t$ value $=4.519$. This result $(\rho=0.000, S D=15.35)$ showed an increase in the use of software SketchUp after treatment. This finding indicates that the learning method that uses the basic version of the software Google SketchUp can improve students' learning achievements in Engineering Mathematics 1 (BA101).
\end{abstract}

Keywords: visualization skills, geometry, Sketch Up software

* Pensyarah Kanan di Jabatan Matematik, Sains \& Komputer, Politeknik Kota Bharu, Kelantan 


\subsection{Pengenalan}

Dalam pembelajaran topik geometri bagi subjek matematik kejuruteraan satu, pelajar perlu membayangkan bentuk sebenar pandangan-pandangan ortografik objek dalam bentuk tiga dimensi (3D) apabila menjawab soalan yang berkaitan pengiraan isipadu. Kebolehan visualisasi objek mempunyai kaitan dengan kejayaan pelajar dalam menjawab soalan topik tersebut. Teknologi komputer menggunakan perisian 2D dan 3D telah banyak membantu pelajar dalam kebolehan daya visualisasi sesuatu objek. Knight (2000) berpandangan bahawa penggunaan dua dimensi dalam perisian pendidikan adalah bertujuan menjadikan ianya lebih realistik dan mengurangkan kelemahan kognitif pengguna. Menurut Mohd Daud Hamzah (2002), visualisasi merupakan salah satu ketrampilan berfikir dimana keupayaan membayangkan rupabentuk dan memutarkan bayangan tersebut dari pelbagai arah dimana dari dua dimensi dan tiga dimensi apabila dimanipulasikan oleh seseorang. Proses visualisasi objek dalam pembelajaran lukisan unjuran ortografik boleh dipaparkan kepada pelajar melalui persembahan 3D.

Dengan menggunakan perisian SkecthUp versi asas, pelbagai objek boleh dipaparkan dalam bentuk samada objek padat ataupun kerangka dawai pada sistem paksi $\mathrm{x}$, paksi y dan paksi $\mathrm{z}$ dan objek boleh digerakkan mengikut kehendak pengguna. Perisian SkecthUp versi asas merupakan sebuah perisian permodelan 3D yang telah dibeli oleh syarikat Trimble Navigation dari syarikat Google Inc. pada bulan April 2012 (Wikipedia, 2013). Tujuan utama perisian ini adalah untuk menghasilkan lakaran atau lukisan dalam bentuk yang lebih mudah dan menarik dalam bentuk 3D. Penggunaan perisian SkecthUp dalam membuat lakaran objek-objek seperti kiub, kiuboid, piramid, selinder, kon, prisma dan sfera akan membantu pelajar memahami kehendak soalan kerana gabungan objek tersebut boleh diputar mengikut kehendak paksi pengguna dan dari pelbagai arah.

\subsection{Penyataan Masalah}

Mengikut analisis markah latihan yang diberikan kepada pelajar dan keputusan peperiksaan akhir pada semester lepas, terdapat segelintir pelajar menghadapi masalah untuk menguasai topik geometri dalam subjek matematik kejuruteraan satu (BA101). Daripada pemerhatian yang dilakukan, didapati ramai pelajar tidak dapat menjawab dengan baik disebabkan faktor kegagalan mereka menguasai kemahiran menvisualisasi lukisan objek 3D.

Kebanyakkan pelajar dapat menyelesaikan pengiraan formula geometri 2D bagi sesuatu objek, akan tetapi sebahagian dari pelajar menghadapi masalah apabila menyelesaikan pengiraan formula geometri 3D seperti pengiraan isipadu bagi objek yang digabungkan. Keadaan ini bertambah rumit

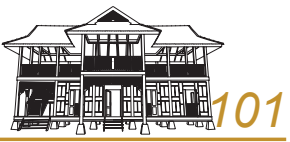


apabila objek yang bergabung tadi dibuang sebahagian lalu membentuk objek baru. Sebagai contoh, Rajah I menunjukkan hal yang demikian.

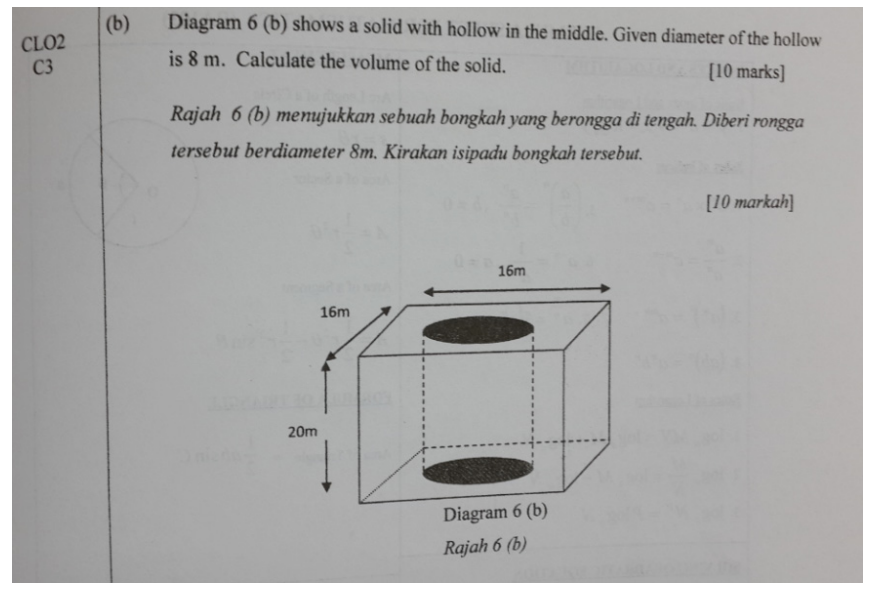

Rajah 1: Contoh soalan bagi objek yang bergabung

\subsection{Objektif Kajian}

Kajian ini bertujuan untuk:

i. mengenalpasti keberkesanan penggunaan perisian SketchUp versi asas dalam topik geometri bagi subjek matematik kejuruteraan satu.

ii. mengetahui persepsi pelajar terhadap kaedah penggunaan perisian SketchUp versi asas dalam topik tersebut.

iii. mengkaji hubungan jantina, jabatan, markah pra dan pos terhadap persepsi pelajar.

\subsection{Sorotan Kajian}

Beberapa kajian telah dijalankan oleh penyelidik dengan menggunakan perisian yang dahulunya dikenali Google SketchUp. Kajian dalam bidang pendidikan yang telah dijalankan oleh Mohd Yazid (2012) menunjukkan bahawa kaedah pembelajaran menggunakan perisian Google SktechUp versi asas ini dapat meningkatkan pencapaian dan minat pelajar terhadap subtopik lukisan unjuran ortografik bagi subjek lukisan teknik kemahiran hidup tingkatan dua. 
Manakala kajian yang telah dilakukan oleh Tan Tong Hock (2011), menunjukkan Modul Pembelajaran GSU yang menggunakan perisian Google SktechUp versi asas berupaya membantu kebanyakkan pelajar sekolah rendah bergerak maju berdasarkan tiga tingkat pemikiran van Hiele utama dan pergerakkan tersebut kebanyakkan berlaku dalam aturan berterusan. Kajian ini juga menonjolkan satu kerangka peralatan teknologi GSU yang praktikal sebagai penggantian dalam membantu para pelajar bergerak maju berdasarkan tingkat pemikiran Geometri van Hiele dan pada akhirnya memudahkan serta menyelesaikan masalah pembelajaran Geometri.

Kajian yang telah dijalankan oleh pensyarah Fakulti Kejuruteraan dan Sains Geoinformasi UTM telah menunjukkan bahawa perisian Google Sketchup Pro 6 amat membantu proses menvisualisasi dalam bidang pemetaan 3D. (Ahmad Abdullah \& Zainal Abidin (2010). Pensyarah Universiti Tun Hussein Onn pula mendapati perisian ini juga membantu dalam proses memvisualisasi objek dan data 3D bagi menentukan perancangan infrastruktur bangunan. (Maslina Md. Najib, 2008). Manakala Noor Azila (2008) juga memperolehi manfaat dari perisian tersebut dalam proses menvisual pemantauan proses bangunan tambahan dalam perancangan merekabentuk bangunan baru di Universiti Tun Hussein Onn. Mereka mendapat manfaat perisian tersebut dari sudut penjimatan masa dan pengurangan kos.

\subsection{Metodologi Kajian}

Kaedah penyelidikan yang dilakukan dalam menjalankan kajian ini ialah dengan menggunakan kaedah tindakan secara eksperimen rekabentuk pra dan pos. Kajian ini dijalankan dengan menggunakan instrumen soalan ujian pra dan ujian pos di samping borang soal-selidik untuk memperolehi data berkaitan persepsi pelajar. Ujian pra digunakan untuk mengesan tahap pencapaian pelajar dalam tajuk geometri dengan kaedah pengajaran tradisional. Manakala ujian pos pula digunakan untuk menguji kesan penggunaan kaedah berasaskan perisian SketchUp dalam memahami dan menjawab soalan topik ini. Instrumen soal selidik pula digunakan untuk mendapat maklum balas daripada pelajar tentang persepsi mereka dalam penggunaan kaedah ini dalam pengajaran dan pembelajaran. Populasi kajian terdiri daripada 30 pelajar semester satu dari Jabatan Kejuruteraan Awam, Jabatan Kejuruteraan Elektrik dan Jabatan Kejuruteraan Mekanikal yang mengambil subjek matematik kejuruteraan satu (BA101) di Politeknik Kota Bharu, Kelantan.

Pada mulanya kumpulan pelajar didedahkan dengan pengajaran menggunakan kaedah tradisional berkaitan dengan topik geometri. Pada akhir sesi pengajaran pelajar ini akan diberi satu set soalan ujian pra bagi menentukan pencapaian mereka terhadap tajuk ini. Pelajar-pelajar akan diberitahu dahulu mengenai topik tersebut sebelum ujian pra dijalankan supaya mereka dapat membuat persediaan awal. Selepas ujian pra, jawapan-jawapan akan dikumpulkan dan dianalisis untuk

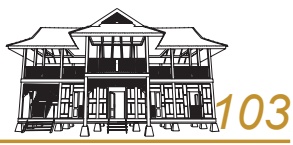


mendapat markah bagi setiap pelajar. Langkah yang berikutnya pelajar akan diajar topik yang sama dengan menggunakan kaedah pembelajaran berasaskan perisian SketchUp.

Satu ujian pos akan dijalankan kepada kumpulan ini sebaik sahaja pengajaran berakhir. Ujian ini bertujuan untuk melihat keberkesanan penggunaan kaedah pembelajaran berasaskan perisian SketchUp yang telah dijalankan ke atas kumpulan pelajar tadi. Mereka juga akan diminta untuk menjawab soal selidik berhubung dengan persepsi mereka kaedah pembelajaran berasaskan perisian SketchUp yang telah digunakan dalam proses pengajaran dan pembelajaran mereka.

Data yang dikumpulkan dianalisis menggunakan perisian SPSS versi 20. Bagi ujian deskriptif, ujian yang digunakan ialah frekuensi, min, sisihan piawai dan peratusan. Manakala ujian inferens pula menggunakan ujian korelasi bagi mendapatkan tahap hubungan pembolehubah. Dapatan kajian ini menjawab persoalan kajian berdasarkan analisis penilaian yang telah dijalankan. Penilaian ini menggunakan skala Likert lima pilihan iaitu Sangat Setuju (SS), Setuju (S), Tidak Pasti (TP), Tidak Setuju (TS) dan Sangat Tidak Setuju (STS). Tafsiran dapatan daripada soal selidik di analisis seperti Jadual I.

Jadual 1: Tafsiran skor min

\begin{tabular}{|c|c|c|}
\hline Kumpulan & Julat & Tahap kecenderungan \\
\hline 1 & $1.00-2.33$ & Rendah \\
\hline 2 & $2.34-3.67$ & Sederhana \\
\hline 3 & $3.68-5.00$ & Tinggi \\
\hline
\end{tabular}

Sumber: Landell (1997)

\subsection{Keputusan dan Perbincangan}

Keputusan ujian kesahan data yang dilakukan menunjukkan nilai koeffisen kebolehpercayaan Cronbach's alpha adalah 0.796. Menurut Sekaran (2003), nilai Cronbach's alpha yang kurang daripada 0.60 dianggap lemah, nilai antara 0.7 boleh diterima dan nilai 0.8 ke atas adalah baik. Keputusan ujian keesahan data menunjukkan bahawa kesahan soalan soal selidik berada pada tahap baik dan boleh diterima. Ujian taburan normal pula menunjukkan taburan data berada pada kedudukan normal ekoran dari nilai Skewness ialah -0.22.

Hasil dari analisa data juga telah mendapati keputusan nilai min bagi kedua-dua ujian tersebut min yang diperolehi oleh pelajar bagi ujian pra adalah $56.83 \%$ dan min bagi ujian pos adalah $69.50 \%$. Manakala perbezaan bagi kedua-dua ujian adalah $12.67 \%$. Jelasnya terdapat peningkatan peratus min di antara keputusan ujian pra dan ujian pos. Secara keseluruhan, hasil kajian mendapati bahawa

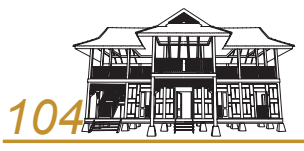

TENIAE 
persepsi pelajar berada pada tahap yang tinggi $(M=4.07, S D=1.015)$ terhadap kaedah penggunaan perisian SketchUp di dalam kelas matematik kejuruteraan satu. Jadual 2 menunjukkan skor min dan sisihan piawai bagi skor persepsi.

Jadual 2 : Skor min dan sisihan piawai bagi skor persepsi

\begin{tabular}{|c|c|c|c|c|c|}
\hline $\mathbf{N}$ & \multicolumn{2}{|c|}{ Skor Minima } & Skor Maksima & Skor Min & Sisihan Piawai \\
\hline Skor Persepsi & 30 & 1.00 & 5.00 & 4.07 & 10.15 \\
\hline
\end{tabular}

Hasil dari ujian-t dalam Jadual 3 telah menunjukkan bahawa terdapat perbezaan yang signifikan antara markah pra dan pos dimana nilai $t=4.519$. Keputusan ini $(\rho=0.000, S D=15.35)$ menunjukkan berlakunya peningkatan dalam penggunaan perisian SketchUp di dalam kelas matematik kejuruteraan 1 setelah dilakukan rawatan. Hasil dari analisa data memberikan nilai $\rho>\alpha$ dan keputusan ini ( $\rho$ $=1.00, \alpha=0.05$ ) menunjukkan bahawa tidak terdapat hubungan yang signifikan antara jantina, jabatan, markah pra dan pos terhadap persepsi pelajar.

Jadual 3: Analisis Ujian-t Bagi Ujian Pra dan Ujian Pos

\begin{tabular}{|l|l|c|c|c|c|c|c|}
\hline Mod Pengajaran & \multicolumn{2}{|l|}{ Bilangan Sampel } & Min & $\begin{array}{c}\text { Sisihan } \\
\text { Piawai }\end{array}$ & df & Nilai-T & Nilai P \\
\hline Tradisional & 30 & 58.83 & 18.39 & 29 & 4.519 & .000 \\
\hline SketchUp & 30 & 69.50 & & 18.39 & & & \\
\hline
\end{tabular}

Paras signifikan $\mathrm{P}<0.05$

Dapatan yang diperolehi menerusi analisis korelasi dari Jadual 4 merumuskan bahawa wujud hubungan yang negatif pada nilai pekali korelasi Pearson antara persepsi dengan jantina $(-0.20)$, markah pra (-0.691) dan markah pos (-0.581). Berdasarkan kepada nilai pekali Davies (1971), tahap kekuatan korelasi yang ditunjukkan oleh antara persepsi dengan jantina, markah pra dan markah pos adalah pada skala yang rendah. Oleh itu, berdasarkan kepada maklumat ini maka dapatlah dirumuskan bahawa jantina, markah pra dan pos tidak mempengaruhi persepsi pelajar tentang kaedah penggunaan perisian SketchUp di dalam kelas matematik kejuruteraan satu. 
Jadual 4: Hubungan data demografi dengan persepsi

\begin{tabular}{|l|c|c|c|c|}
\hline & Jantina & Jabatan & $\begin{array}{c}\text { Markah } \\
\text { Pra }\end{array}$ & $\begin{array}{c}\text { Markah } \\
\text { Pos }\end{array}$ \\
\hline Pearson Correlation & -0.200 & 0.450 & -0.691 & -0.589 \\
Sig. (2-tailed) & 0.13 & 0.13 & 0.000 & 0.001 \\
N & 30 & 30 & 30 & 30 \\
\hline
\end{tabular}

\subsection{Kesimpulan}

Secara keseluruhannya objektif untuk mengenalpasti keberkesanan penggunaan perisian SketchUp versi asas dalam topik geometri bagi subjek matematik kejuruteraan satu adalah tercapai. Jelas sekali terdapat perbezaan yang signifikan antara markah pra dan pos dimana terdapat peningkatan dalam penggunaan penggunaan perisian SketchUp di dalam kelas matematik kejuruteraan satu. Hasil kajian ini juga mendapati bahawa persepsi pelajar terhadap kaedah penggunaan perisian SketchUp di dalam kelas matematik kejuruteraan satu berada pada tahap tinggi. Ini bermakna kebanyakkan pelajar berpandangan penggunaan perisian SketchUp versi asas dapat membantu mereka memahami topik geometri dengan lebih jelas lagi. Manakala jantina, jabatan, markah pra dan pos tidak mempengaruhi persepsi pelajar tentang kaedah penggunaan perisian SketchUp di dalam kelas matematik kejuruteraan satu.

Kesimpulannya, kaedah pengajaran dan pembelajaran menggunakan perisian SketchUp versi asas memberi kesan positif berbanding kaedah tradisional. Kaedah ini dapat membantu meningkatkan kemahiran daya visualisasi pelajar seterusnya menyebabkan peningkatan dalam pencapaian dan minat pelajar. 


\section{Rujukan}

Ahmad Abdullah \& Zainal Abidin (2010). Pemetaan Tiga Dimensi (3D) Dan Visualisasi Menggunakan Google Sketchup Pro 6 (KajianKes :Sebahagian Daripada Kolej Kediaman Rahman Putra). Fakulti Kejuruteraan dan Sains Geoinformasi, Penerbit Universiti Teknologi Malaysia, 2010.

Knight, M. (2000). System And Software Visualization. Durham, UK: World Scientific.

Landell, H. K. (1997). Management by Menu. London: Wiley and Sons Inc.

Mohd Daud Hamzah (2002). Kertas ceramah bengkel peningkatan kualiti kaedah pengajaran pembelajaran subjek matematik dan pendidikan Islam bagi program matrikulasi Kementerian Pendidikan Malaysia. Kuala Lumpur. 5-8 Ogos, 2002.

Maslina Md. Najib (2008). Visualisasi Data 3D Di Dalam Perisian Google Sketchup Bagi Menentukan Perancangan Infrastruktur Bangunan, Fakulti Kejuruteraan Awam dan Alam Sekitar, Universiti Tun Hussein Onn Malaysia, 2008

Mohd Yazid (2012). Keberkesanan Penggunaan Perisian Google Sketch-Up Terhadap Peningkatan Pencapaian Dan Minat Pelajar Dalam Subtopik Lukisan Unjuran Ortografik Tingkatan Dua. Prosiding ke 194 Persidangan Kebangsaan Penyelidikan Dan Inovasi Dalam Sistem Pendidikan Dan Latihan Teknikal Dan Vokasional 2012, Politeknik Nilai Negeri Sembilan, 25-26 Sept 2012.

Noor Azila Mohd Puaat (2008). Aplikasi Google Sketchup Bagi Menvisual Pemantauan Proses Bangunan Tambahan Di Dalam Perancangan Merekabentuk Bangunan Baru. Fakulti Kejuruteraan Awam dan Alam Sekitar, Universiti Tun Hussein Onn Malaysia, 2008.

Tan Tong Hock (2011). Assisting Primary School Children To Progress Through The Van Hiele's Levels Of Geometry Thinking Using Google Sketchup. Diakses dari http://www.fp.utm.my/ePusatSumber/Tb psm_list_Detail.asp?key=\{90EB35DE-32EA-4CFE-AC4F-59F66257E7E4\}.

Uma Sekaran (2003). Research Method for Business; A Skill Building Approach, 4th edition, John Wiley \& Sons.

Wikipedia (2013). What is Sketchup. Diakses dari http://www.wikipedia.org/.

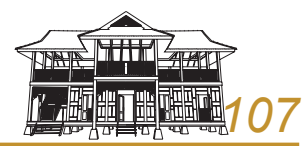


